\title{
Aminolysis Reaction of Reactive Diesters with Amine
}

\author{
Naoya Ogata, Kohei SanuI, and Hiroyuki Nakamura \\ Department of Chemistry, Sophia University, \\ 7, Kioi-cho, Chiyoda-ku, Tokyo 102, Japan.
}

(Received November 2, 1977)

\begin{abstract}
Diesters having hydroxyl groups can react with diamines under mild conditions to form polyamides having pendant hydroxyl groups. The reactivity enhancement owing to the hydroxyl group was investigated in terms of the aminolysis reaction of aliphatic or heterocyclic hydroxyl diesters with butylamine. Apparent rate constants could be expressed in the following equation:

$$
k_{\mathrm{obs}}=k_{1}\left[\mathrm{BuNH}_{2}\right]+k_{2}\left[\mathrm{BuNH}_{2}\right]^{2}
$$

The enhancement effect of the hydroxyl group on the aminolysis reaction was interpreted either as the polarity change of the ester carbonyl group, in the case of heterocyclic diesters, or as the intermolecular hydrogen bonding with amine, in the case of aliphatic diesters.

KEY WORDS Polyamide / Hydroxyl Diesters / Heterocyclic Diesters / Aminolysis / Hydrogen Bonding /
\end{abstract}

Polycondensation reactions of diesters with diamines are usually carried out in a molten state at elevated temperatures because the reactivity of ordinary diesters is not sufficiently high enough to carry out the polycondensation under mild conditions, unless one uses so-called active diesters, such as $p$-nitrophenyl ester. However, previous papers ${ }^{1-3}$ revealed that the reactivity of ordinary diesters, such as methyl ester, is so greatly enhanced by introducing hetero atoms or heterocyclic groups that the polycondensation of these diesters can take place under mild conditions to produce the corresponding polyamides. For instance, tartarate or mucate, which have hydroxyl groups, ${ }^{2}$ or diesters having $\gamma$-pyrone moiety ${ }^{3}$ can react with diamine even at room temperature to form polyamides.

This paper deals with the aminolysis reaction of these reactive diesters having hydroxyl groups in order to investigate the reactivity enhancement owing to the hydroxyl groups. Kinetical measurements of various hydroxyl diesters were carried out using butylamine and the reaction mechanism is discussed.

\section{EXPERIMENTAL}

\section{Materials}

The following diesters were obtained by the esterification of the corresponding dicarboxylic acids according to a conventional method and were purified by distillation or recrystallization.

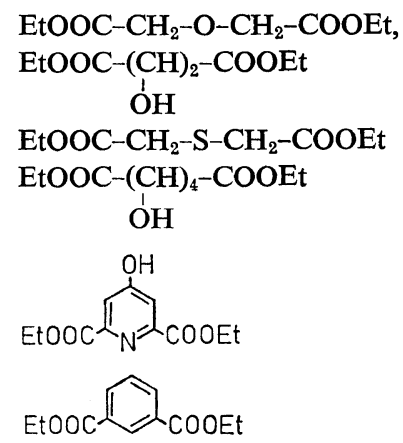

Commercially available diethyl succinate, oxalate, or acetone dicarboxylate were used after purification by distillation.

Diethyl 3,4-dihydroxyadipate (DHA) was synthesized by the oxidation of trans-2-butenedicarboxylate with hydrogen peroxide in 2-methyl-2propanol at $0^{\circ} \mathrm{C}$, in the presence of osmium tetraoxide as a catalyst. 
N. Ogata, K. Sanui, and H. Nakamura

\section{EtOOC- $\mathrm{CH}_{2} \mathrm{CH}=\mathrm{CHCH}_{2} \mathrm{COOEt}$ \\ $\frac{\mathrm{H}_{2} \mathrm{O}_{2}}{\mathrm{OsO}_{4}} \rightarrow$ EtOOC- $\mathrm{CH}_{2} \mathrm{CH}-\mathrm{CHCH}_{2} \mathrm{COOEt}$ $\stackrel{\mathrm{O}}{\mathrm{H}} \stackrel{\mathrm{O}}{\mathrm{OH}}$ \\ (DHA)}

Diethyl 2,6-diphenyl-3,5-tetrahydropyronedicarboxylate (THD) ${ }^{5}$ was synthesized from diethyl acetonedicarboxylate and benzaldehyde, by bubbling hydrogen chloride under cooling with water.

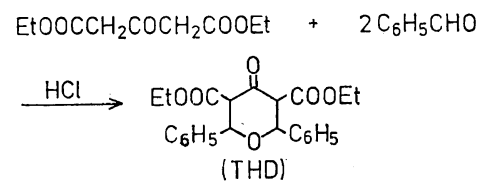

Diethyl 1,4-dioxa-2,6-cyclohexanedicarboxylate (OCD) was synthesized ${ }^{6}$ from trioxane and diethyl diglycolate in the presence of sulfuric acid.

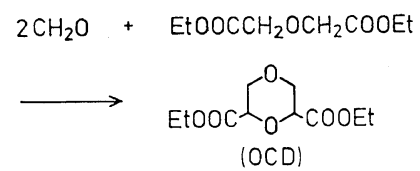

Diethyl chelidonate (DEC) was prepared ${ }^{7}$ from diethyl oxalate and acetone in the presence of sodium ethoxide.



Diethyl 3,4-dihydroxy-2,5-furandicarboxylate (DHF) was synthesized ${ }^{8}$ from diethyl oxalate and diethyl diglycolate in the presence of sodium ethoxide. The same procedure afforded diethyl 3,4-dihydroxy-2,5-thiophenedicarboxylate (DHT), using diethyl dithioglycolate instead of diglycolate.

$$
\begin{aligned}
& \text { EtOOCCOOEt + EtOOCCH } \mathrm{OCH}_{2} \text { COOEt } \\
& \stackrel{\mathrm{NaOEt}}{\longrightarrow} \underset{\text { EtOOCC }}{\mathrm{ODHF}} \mathrm{CHOEt}_{\mathrm{COOH}}^{\mathrm{OH}} \\
& \text { EtOOCCOOEt + EtOOCCH } \mathrm{SCH}_{2} \mathrm{COOEt}
\end{aligned}
$$

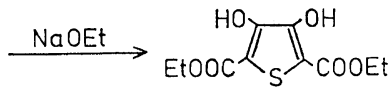

\begin{tabular}{|c|c|c|c|c|c|}
\hline \multirow{2}{*}{ Ester } & \multirow{2}{*}{$\mathrm{mp}_{{ }^{\circ} \mathrm{C}}^{[\mathrm{bp}]}$} & \multicolumn{2}{|c|}{$\begin{array}{c}\text { Elemental Analysis } \\
\text { (calcd) }\end{array}$} & \multirow{2}{*}{$\mathrm{IR}, \mathrm{cm}^{-1}$} & \multirow{2}{*}{$\begin{array}{l}\text { NMR, } \\
\delta, \text { ppm }\end{array}$} \\
\hline & & $\mathrm{C} \%$ & $\mathrm{H} \%$ & & \\
\hline 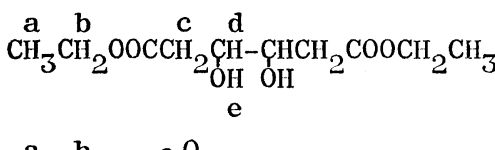 & $75-77$ & $52.5(51.3)$ & $8.1(7.8)$ & $\begin{array}{ll}\nu_{\mathrm{OH}} & 3370,3460 \\
\nu_{\mathrm{C}=\mathrm{O}} & 1710,1732\end{array}$ & $\begin{array}{l}\text { a } 1.4, \text { c } 2.7 \\
\text { e } 3.45 \\
\text { b, d } 4.3\end{array}$ \\
\hline $\mathrm{C}_{6} \mathrm{CH}_{5} \mathrm{COOCH}_{2} \mathrm{CH}_{3}$ & $\begin{array}{l}{[215-216]} \\
(0.1 \mathrm{~mm})\end{array}$ & $71.0(69.7)$ & $6.0(6.1)$ & $\begin{array}{l}\nu_{\mathrm{C}=\mathrm{O}} 1679,1741 \\
\nu_{\mathrm{C}=\mathrm{C}} 1644\end{array}$ & $\begin{array}{l}\text { a, } 1.1, \text { b } 4.0 \\
\text { c, d } 5.0 \\
\text { e } 7.2\end{array}$ \\
\hline$\underset{\mathrm{CH}_{3}}{\mathrm{a}} \stackrel{\mathrm{b}}{\mathrm{CH}_{2}} \mathrm{OOC}^{\mathrm{c}}$ & $\begin{aligned} & {[71-72] } \\
&(0.02 \mathrm{~mm})\end{aligned}$ & $47.5(51.7)$ & $7.4(6.9)$ & $\begin{array}{ll}\nu_{\mathrm{CH}} & 2960 \\
\nu_{\mathrm{C}=0} & 1750\end{array}$ & $\begin{array}{l}\text { a } 1.3, \text { d } 2.63 \\
\text { b, c } 4.1\end{array}$ \\
\hline $\mathrm{CH}_{3} \mathrm{CH}_{2} \mathrm{CH}_{\mathrm{c}^{-}}$ & 63 & $55.2(55.0)$ & $5.1(5.0)$ & $\nu_{\mathrm{C}=\mathrm{o}} 1652,1739$ & $\begin{array}{l}\text { a } 1.4, \text { b } 4.4 \\
\text { c } 7.07\end{array}$ \\
\hline $\mathrm{COOCH}_{2} \mathrm{CH}_{3}$ & $198-199$ & $50.9(49.2)$ & $5.3(5.0)$ & $\begin{array}{ll}\nu_{\mathrm{C}=\mathrm{O}} & 1683 \\
\nu_{\mathrm{C}=\mathrm{C}} & 1580\end{array}$ & $\begin{array}{l}\text { a } 1.3, \text { b } 4.3 \\
\text { c } 10.0\end{array}$ \\
\hline$\underset{\mathrm{CH}_{3}}{\mathrm{a}} \mathrm{CH}_{2} \mathrm{OOC}_{\mathrm{S}}$ & $142-143$ & $45.7(46.2)$ & $4.8(4.6)$ & $\nu_{\mathrm{C}=0} \quad 1679$ & $\begin{array}{l}\text { a } 1.3, \text { b } 4.3 \\
\text { c } 9.28\end{array}$ \\
\hline
\end{tabular}

$$
\begin{aligned}
& \text { (DHT) }
\end{aligned}
$$

Table I. Characterization of diesters 
All of these synthesized diesters gave satisfactory results of elemental analyses and showed IR and NMR spectra compatible with their expected structures. Melting or boiling points and analytical data of these diesters are summarized in Table I.

All of reagents and solvents were purified before use.

\section{Kinetic Measurement}

A solution of diesters in dioxane was mixed with a given amount of butylamine in the presence or absence of a catalyst, and the solution was placed in a water bath kept at a constant temperature. Rates of the aminolysis reaction were followed by measuring the amount of liberated ethanol by means of a gaschromatographic analysis, which was carried out by using a flame-ionization type JEC-20KFP (Nippon Denshi Co.) with a column of triton $\mathrm{X}-100$.

\section{Spectrum Measurement}

The IR spectrum was measured by a Hitachi model 215 infrared spectrophotometer either in solutions or in $\mathrm{KBr}$ disks. The NMR spectrum of diesters was measured by a Hitachi R-22 or R-24 nuclear magnetic resonance spectrometer in tetrachloromethane, chloroform- $d$, or dimethyl sulfoxide- $d_{6}$ solutions. ${ }^{13} \mathrm{C}-\mathrm{NMR}$ measurements were carried out in dioxane or dimethyl sulfoxide solutions by a Hitachi R-42 Fourier Transform NMR. Tetramethylsilane was used as a standard.

\section{RESULTS AND DISCUSSION}

Various diesters were allowed to react with an excess amount of butylamine in dioxane at $60^{\circ} \mathrm{C}$. The apparent rate constants of the aminolysis reaction, which were obtained as a first order reaction, are summarized in Tables II and III.

Tables II and III indicate that apparent rate constants $k_{\text {obs }}$ for the reaction of such hydroxyl diesters as tartarate or mucate, and for the reaction of diesters having furan or $\gamma$-pyrone nuclei, are $10^{3}$ to $10^{4}$ times as large as those of ordinary diesters which do not have hetero atom groups. The aminolysis reaction of ester with amine has been extensively studied by Menger, ${ }^{9}$ who found
Table II. Observed rate constants for the condensation of various aliphatic diesters with butylamine ${ }^{a}$ in dioxane at $60^{\circ} \mathrm{C}$

\begin{tabular}{|c|c|c|}
\hline $\begin{array}{l}\text { EtOOC-R-COOEt } \\
\quad \mathbf{R}\end{array}$ & $C_{\mathrm{Eo}}^{\mathrm{b}} \times 10^{3}, M$ & $k_{\mathrm{obs}}, \mathrm{sec}^{-1}$ \\
\hline Diethyl oxalate & 6.44 & $1.8 \times 10^{-3}$ \\
\hline$-\mathrm{CH}_{2-}^{-}$ & 10.05 & $<10^{-8}$ \\
\hline$-\left(\mathrm{CH}_{2}\right)_{2}-$ & 9.89 & $<10^{-8}$ \\
\hline$-\mathrm{CH}_{2} \mathrm{COCH}_{2}-$ & 10.33 & $8.5 \times 10^{-8}$ \\
\hline$-\mathrm{CH}_{2} \mathrm{OCH}_{2-}$ & 10.84 & $6.5 \times 10^{-7}$ \\
\hline$-\mathrm{CH}_{2} \mathrm{SCH}_{2-}^{-}$ & 10.84 & $1.5 \times 10^{-7}$ \\
\hline $\begin{array}{c}-(\mathrm{CH})_{2}- \\
\stackrel{\mathrm{OH}}{ }\end{array}$ & 10.87 & $1.1 \times 10^{-8}$ \\
\hline $\begin{array}{c}-\mathrm{CH}_{2}(\mathrm{CH})_{2} \mathrm{CH}_{2}- \\
\text { OH }\end{array}$ & 8.70 & $1.2 \times 10^{-5}$ \\
\hline $\begin{array}{c}-(\mathrm{CH})_{4^{-}} \\
\text {OH }\end{array}$ & 9.98 & $2.3 \times 10^{-4}$ \\
\hline
\end{tabular}

${ }^{a}$ Concn of Bu- $\mathrm{NH}_{2}, 5.00 \times 10^{-1} \mathrm{M}$.

b Initial concentration of ester group.

Table III. Observed rate constants for the condensation of various heterocyclic diesters with butylamine $^{\mathrm{a}}$ in dioxane at $60^{\circ} \mathrm{C}$

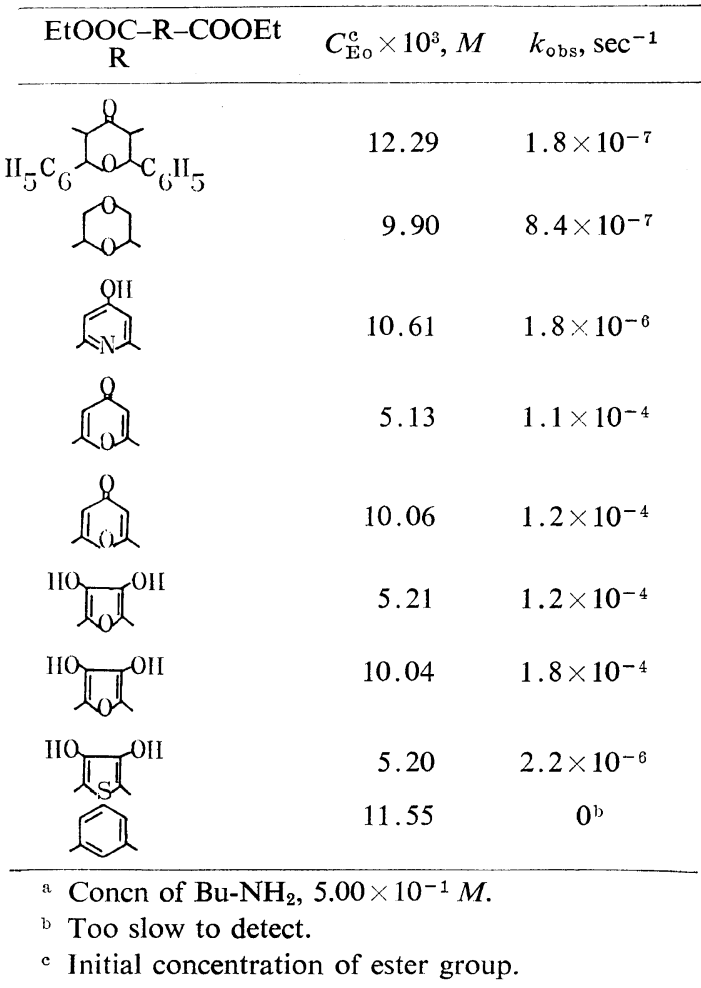


that the apparent rate constants of the aminolysis reaction can be expressed as a function of amine when the amount of amine is used in excess. When the values of $k_{\text {obs }} /\left[\mathrm{BuNH}_{2}\right]$ are plotted as a function of $\left[\mathrm{BuNH}_{2}\right]$, a good linear relation-

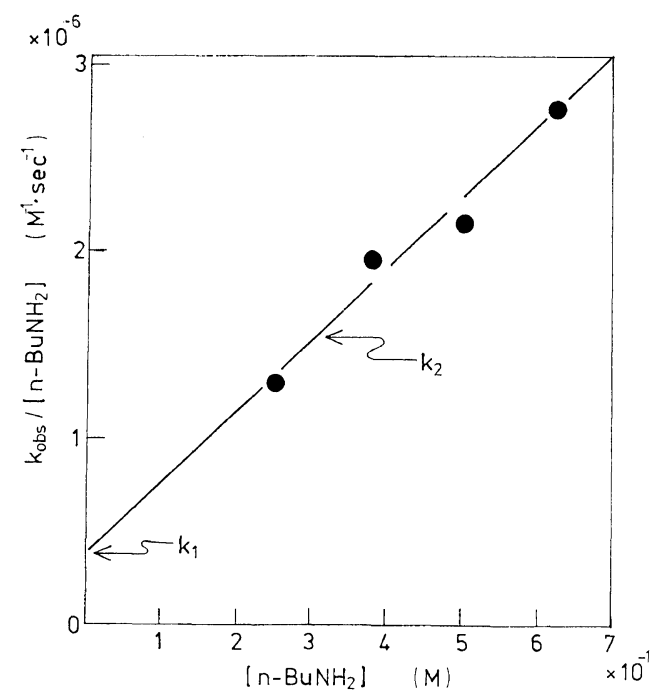

Figure 1. Plot of observed rate constants for butylaminolysis of diethyl tartarate in dioxane at $60^{\circ} \mathrm{C}$ vs. [butylamine]; initial ester concn, $1.087 \times$ $10^{-2} M$. ship is observed, as shown in Figure 1, and $k_{\text {obs }}$ can be expressed in the following equation, as Menger found for the aminolysis reaction of ordinary esters.

$$
k_{\mathrm{obs}}=k_{1}\left[\mathrm{BuNH}_{2}\right]+k_{2}\left[\mathrm{BuNH}_{2}\right]^{2}
$$

The apparent rate constants $k_{1}$ and $k_{2}$ can be determined from the intercepts and slopes of the straight lines, as shown in Figure 1.

In the case of diethyl mucate, which is $2,3,4,5$ tetrahydroxyadipate, DHF or DHT, a simple relation between $k_{\text {obs }}$ and $\left[\mathrm{BuNH}_{2}\right]$ was observed, as shown in the following equation (2).

$$
k_{\text {obs }}=k_{1}\left[\mathrm{BuNH}_{2}\right]
$$

The apparent rate constants $k_{1}$ and $k_{2}$ for the aminolysis reaction of various diesters are summarized in Table IV.

It is known $^{10}$ that the aminolysis reaction of ester is accelerated by tertiary amines such as triethylenediamine (Dabco). Therefore, various tertiary amines or quaternary ammonium salts were added to the mixed solution of diesters and butylamine, and the rates of the aminolysis reaction were measured; these are summarized in Table V. Table $\mathrm{V}$ indicates that quaternary ammonium salts or trialkyl amines accelerate the

Table IV. Values of $k_{1}$ and $k_{2}$ for the condensation of various diesters

\begin{tabular}{|c|c|c|c|c|}
\hline $\begin{array}{c}\text { EtOOC-R-COOEt } \\
\text { R }\end{array}$ & $C_{\mathrm{Eo}}^{\mathrm{b}} \times 10^{3}, M$ & Temp, ${ }^{\circ} \mathrm{C}$ & $k_{1}, M^{-1} \sec ^{-1}$ & $k_{2}, M^{-2} \sec ^{-1}$ \\
\hline Diethyl oxalate & 6.44 & 30 & - & $4.7 \times 10^{-3}$ \\
\hline$-(\mathrm{CH})_{2}-$ & 10.87 & 60 & $2.7 \times 10^{-7}$ & $3.9 \times 10^{-8}$ \\
\hline$-\mathrm{CH}_{2}(\mathrm{CII})_{2} \mathrm{CII}_{2}-$ & 4.35 & 30 & $3.0 \times 10^{-6}$ & $4.0 \times 10^{-8}$ \\
\hline \multirow[t]{6}{*}{$-(\mathrm{CH})_{4}^{-}$} & 9.98 & 60 & $4.7 \times 10^{-4}$ & - \\
\hline & 10.61 & 60 & $9.4 \times 10^{-7}$ & $5.9 \times 10^{-6}$ \\
\hline & 5.21 & 60 & $2.3 \times 10^{-4}$ & - \\
\hline & 5.20 & 60 & $4.3 \times 10^{-6}$ & - \\
\hline & 5.13 & 20 & - & $2.7 \times 10^{-4}$ \\
\hline & 10.06 & 60 & $2.6 \times 10^{-5}$ & $4.5 \times 10^{-4}$ \\
\hline
\end{tabular}
with butylamine ${ }^{a}$ in dioxane

a Concn of Bu- $\mathrm{NH}_{2}, 2.50-6.20 \times 10^{-1} \mathrm{M}$.

$\mathrm{b}$ Initial concentration of ester group. 
Table V. Effects of various basic catalysts on the condensation of diethyl esters with butylamine ${ }^{a}$ in dioxane at $30^{\circ} \mathrm{C}$

\begin{tabular}{|c|c|c|c|}
\hline Ester & Catalyst & $k_{\mathrm{obs}}, \mathrm{sec}^{-1}$ & $k_{\text {obs }}$, relative \\
\hline \multirow{6}{*}{$\mathrm{DHF}^{\mathrm{b}}$} & None & $2.9 \times 10^{-5}$ & 1 \\
\hline & Pyridine & $2.9 \times 10^{-5}$ & 1.0 \\
\hline & $\begin{array}{l}N, N \text {-Dimethyl- } \\
\text { aniline }\end{array}$ & $4.6 \times 10^{-5}$ & 1.6 \\
\hline & $\mathrm{Bu}_{3} \mathrm{~N}$ & $6.1 \times 10^{-5}$ & 2.1 \\
\hline & Dabco & $1.2 \times 10^{-4}$ & 4.3 \\
\hline & $\mathrm{Bu}_{4} \mathrm{NBr}$ & $1.5 \times 10^{-4}$ & 5.1 \\
\hline \multirow{6}{*}{ Mucate $^{c}$} & None & $9.9 \times 10^{-5}$ & 1 \\
\hline & Pyridine & $1.1 \times 10^{-4}$ & 1.1 \\
\hline & $\begin{array}{l}N, N \text {-Dimethyl- } \\
\text { aniline }\end{array}$ & $1.1 \times 10^{-4}$ & 1.1 \\
\hline & $\mathrm{Bu}_{4} \mathrm{NClO}_{4}^{\mathrm{d}}$ & $3.3 \times 10^{-4}$ & 3.4 \\
\hline & $\mathrm{Bu}_{4} \mathrm{NBr}^{\mathrm{d}}$ & $3.9 \times 10^{-4}$ & 3.9 \\
\hline & $\mathrm{Bu}_{3} \mathrm{~N}$ & $5.0 \times 10^{-4}$ & 5.1 \\
\hline
\end{tabular}

a Concn of $\mathrm{BuNH}_{2}, 5.00 \times 10^{-1} M$.

b Concn of ester groups $\left(C_{\mathrm{Eo}}\right), 5.21 \times 10^{-3} M$; concn of catalyst, $2.50 \times 10^{-1} \mathrm{M}$.

c $C_{\mathrm{Eo}}, 5.48 \times 10^{-3} \mathrm{M}$; concn of catalyst, $2.50 \times$ $10^{-1} M$.

d Concn of catalyst, $2.0 \times 10^{-1} \mathrm{M}$.

aminolysis reaction, while $N, N$-dimethylaniline or pyridine does not.

Menger ${ }^{9}$ has proposed as the mechanism of the aminolysis reaction that a tetrahedron intermediate is formed by a quick attack of amine on an ester carbonyl group, which is accompanied by an equilibrium, and this intermediate product yields amide and alcohol as a rate-determining step:

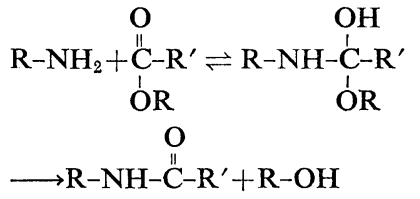

In order to investigate the quick attack of amine on an ester carbonyl group, the electron density of the ester carbonyl group should be determined. ${ }^{13} \mathrm{C}$-chemical shifts of the acyl carbon are known ${ }^{11}$ to reflect electron densities of the acyl carbon atom. Therefore, ${ }^{13} \mathrm{C}$-chemical shifts of the acyl carbons of various diesters were compared with $k_{\mathrm{obs}}$ values of the aminolysis reaction. Diethyl succinate or diethyl isophthalate was taken as a standard in aliphatic or heterocyclic series, respectively. As shown in Table VI,
Table VI. ${ }^{13}$ C-NMR Chemical shifts of acyl of various diethyl esters

\begin{tabular}{|c|c|c|}
\hline $\begin{array}{l}\text { EtOOC-R-COOEt } \\
\quad \mathrm{R}\end{array}$ & $\underset{\left(60^{\circ} \mathrm{C}\right)}{\log k_{\text {obs }}}$ & $\delta_{\mathrm{c}}, \mathrm{ppm}^{\mathrm{a}}$ \\
\hline$-\left(\underset{\mathrm{OII}}{(\mathrm{CII})} 4^{-}\right.$ & -3.63 & 173.49 \\
\hline$-\left(\mathrm{OII}^{-}\right)^{-}$ & -5.97 & 172.41 \\
\hline & $\leq-7$ & 172.41 \\
\hline$-\mathrm{ClI}_{2} \mathrm{OCII}_{2}-$ & -6.19 & 170.49 \\
\hline$-\mathrm{CH}_{2} \mathrm{COCHI}_{2}-$ & -7.07 & 167.40 \\
\hline & 一 & 165.24 \\
\hline & -5.65 & 162.08 \\
\hline & -3.92 & 160.16 \\
\hline III & -3.76 & 158.38 \\
\hline Oxalate & -2.75 & 158.69 \\
\hline
\end{tabular}

${ }^{a}$ Chemical shifts from TMS.

heterocyclic diesters which are reactive toward the aminolysis reaction show a great shift of the peaks connected with the acyl carbon atoms. Therefore, the electron density of these heterocyclic diesters must be sufficiently low to be subjected to an easy attack of amine. On the other hand, hydroxyl diesters which are also reactive toward the aminolysis reaction did not exhibit a significant shift of the acyl carbon peak. IR spectra of these aliphatic hydroxyl diesters also did not exhibit any systematic shift of the absorption owing to the carbonyl group of the esters. These results suggest that the high reactivity of aliphatic hydroxyl diesters must be due to another reason which is not primarily related with the electron density of the carbonyl group of the esters.

The reactivity enhancement owing to the hydroxyl group for the aminolysis reaction of aromatic hydroxyl diesters has been studied by Menger. ${ }^{9}$ Menger and coworkers reported that the aminolysis reaction of aromatic esters is greatly enhanced by substituting with a hydroxyl group at the ortho position of an aromatic nucleus. A strong intramolecular hydrogen bonding between the hydroxyl and ester carbonyl groups may reduce the electron density to such an extent that an easy attack of amine may take place. Thus, $o$-hydroxyl salicylate can react with 
amine with a much faster rate than that for benzoate.<smiles>[R20]C1=C[Te]Oc2ccccc21</smiles>

The same reason as the ortho effect would explain the high reactivity of the heterocyclic diesters having hydroxyl groups, because IR and ${ }^{13} \mathrm{C}-\mathrm{NMR}$ spectra indicate a change in the electron density of the carbonyl group for these heterocyclic diesters.<smiles>[R]OC(O)c1[X]([R])cccc1O</smiles>

On the other hand, no systematic change in electron density of the ester carbonyl group was observed in the case of aliphatic hydroxyl diesters. The reactivity enhancement of aliphatic hydroxyl diesters may be ascribed either to the hydrogenbonding of the hydroxyl group with the approaching amine or to a rapid transformation of a tetrahedron intermediate, which is formed by an attack of amine on an ester carbonyl group at the intermediate stage, into amide and alcohol.<smiles>[R][R]NC(=O)C(O)O[R][R]</smiles>

The apparent rates of the aminolysis reaction of aliphatic hydroxyl diesters are greatly influenced by the polarity of solvents, as reported in a previous paper. ${ }^{2}$ The solvent effect may relate either to the hydrogen bonding or to the rapid transformation of the tetrahedron intermediate.
As described before, the rates of the aminolysis reaction of mucate, DHF or DHT, can be expressed in the simple form of eq 2 without having a second term of $k_{2}$. This would be explained by the reason that the transformation of the tetrahedron intermediate into amide, which is the ratedetermining step, may be very fast.

Acknowledgement. The authors thank Mr. H. Kumon and Miss K. Yamada of the Shin Nippon Zitsugyo Co. for measuring ${ }^{13} \mathrm{C}-\mathrm{NMR}$ spectra. Thanks are also due to Dr. Y. Shimozato for his advice in synthesizing various diesters.

\section{REFERENCES}

1. N. Ogata, Y. Hosoda, and G. Suzuki, Polym. J., 6, 416 (1974).

2. N. Ogata, K. Sanui, and H. Nakamura, J. Polym. Sci., Polym. Chem. Ed., 14, 783 (1976).

3. N. Ogata and K. Shimamura, J. Polym. Sci., Polym. Chem. Ed., 13, 1711 (1975).

4. R. P. Linstead, L. N. Owen, and R. F. Webb, J. Chem. Soc., 1225 (1953).

5. R. Conubert and P. Robinet, Bull. Soc. Chim. Fr., 1(5), 90 (1934).

6) C. A. de Bruyn and W. Alberda van Ekenstein, Rec. Trav. Chim., 21, 313 (1902).

7. A. H. Blatt, Ed., "Organic Syntheses," Vol. 2, Organic Syntheses, Inc., 1955, p 126.

8. T. B. Johnson and C. O. Johns, Am. Chem. J., 36, 290 (1906).

9. F. F. Menger and J. H. Smith, J. Am. Chem. Soc., 91, 5346 (1969); ibid., 94, 3824 (1972).

10. D. P. N. Satchell and I. I. Secemski, J. Chem. Soc. Sect. B, 1013 (1970).

11. E. F. Mooney and P. H. Winson, "Annual Reviews of NMR Spectcroscopy", Vol. 3, Academic Press, London, 1969, p 158. 